\title{
Profile of children admitted with seizures in a tertiary care hospital in South India
}

\author{
Dr. Saravanan S \\ [Assistant professor, Department of Pediatrics, Meenakshi medical college \& research institute, MAHER \\ University, Tamilnadu, India]
}

\begin{abstract}
Background: Seizure is one of the common causes of childhood hospitalization with significant mortality and morbidity. There is limited data regarding acute seizures episodes form the developing countries. Current study aims to find the common etiology of seizure and classify seizure types and outcome in children presenting to a tertiary center in kanchipuram in south India.

Methods: This was a hospital based prospective study carried out in the Department of Pediatrics, Meenakshi medical college and research institute, kanchipuram from $1^{\text {st }}$ Jan 2010 to $31^{\text {st }}$ Dec 2012.Variables record were demographics, clinical presentations, laboratory tests, brain imaging studies, electroencephalography, diagnosis and hospital course.

Results: A total of 520 patients were admitted for seizures with 300 (57.7\%) males and 220 (42.3\%) females. Among these patients, 268(51.5\%) presented with fever and 388 (74.6\%) of children were less than 6 years of age. Generalized seizures were the most common seizure type (50.2\%). Febrile seizures (36.5\%), seizure disorder (33.2\%), symptomatic seizures (20\%) and space occupying lesions were common etiologies. Abnormal brain images were noted in (25\%) of 424 patients and most common abnormality in space occupying lesion was neurocysticercosis (4\%).
\end{abstract}

Keywords: children, febrile convulsions, generalized seizures, kanchipuram, neuroimaging

\section{Introduction}

Acute seizures are a common neurological symptom in sick children. In patients with fever, they include febrile seizures [1,2], acute symptomatic seizures (e.g. in a child with pyogenic meningitis)[3] or initial seizures in a child with epilepsy or epilepsy syndrome[2]. Worldwide, febrile seizures are the most common type of acute seizures in children[4]. Most are associated with infections and have a good outcome [5]. In tropical countries, febrile seizures are common but the prevalence of acute symptomatic seizures (which have a poorer outcome) may be higher than Western countries [6-8]. The incidence of both acute seizures and febrile status epileptics is higher[2,9] and the outcome is worse since the etiology is different[6,8,10,11]. Acute seizures are therefore a major risk factor for neurological and cognitive impairment [12-14] and for the development of epilepsy [15-17] in children living in these regions.

The incidence is highest in children less than 3 years of age, with a decreasing frequency in older children [18]. Seizures account for about $1 \%$ of all emergency department visits, and about $2 \%$ of visits of children's hospital emergency department visits [19]. In most of the studies, febrile seizures were reported to be the most common type seen in the pediatric population and account for the majority of seizures seen in children younger than 5 years of age [19-20].

Central nervous system (CNS) infections are the main cause of seizures and acquired epilepsy in the developing world [20,21]. Geographical variations determine the common causes in a particular region. Acute seizures are common in meningitis, viral encephalitis and neurocysticercosis and in most cases are associated with increased mortality and morbidity, including subsequent epilepsy [22-25]. The standardized mortality rate (SMR) in patients with a newly diagnosed unprovoked seizure ranges from 2.5 to 4.1 according to the study population and design. The SMR is highest in the youngest patients and in those with symptomatic seizure [26]. In most children with newly diagnosed epilepsy, the long-term prognosis of epilepsy is favorable, and in particular, patients with idiopathic etiology will eventually reach remission [27].

There are limited studies on causes and outcome of acute episode of seizure in developing countries. Most studies had done so far have focused on epilepsy and clinical seizure types [28, 29]. In this study, we therefore analyzed the prevalence of various etiologies, the clinical spectrum of seizure disorders and primary outcome of children admitted with acute seizure disorder. 


\section{Methods}

All children admitted in the pediatric ward with complaints of seizures (including recurrent episodes) in the age group of 1 month to 12 years and children admitted for other complaints and developing seizures during the course of their illness were included. Seizures in developmentally abnormal children were excluded. Furthermore, patients were divided into four age groups: age group (1 month - 1 year), (1-3 years), (4-6 years) and (7-12 years). The following information was obtained from each patient: age, sex, type of seizure, associated symptoms (fever, cough, rhinorrhea, vomiting, diarrhea and headache), and family history of seizure or epilepsy, developmental history. Laboratory test (hemogram, C-reactive protein, serum electrolytes, blood sugar) was done. Neuroimaging; CT scan head or cranial magnetic resonance imaging (MRI), electroencephalography (EEG), CSF analysis was done wherever indicated and results recorded. Final outcome was recorded in four categories: discharged after recovery, left against medical advice (LAMA), mortality and referral to other institutions. Seizure type classification, including generalized tonic-clonic (GTC), absence, myoclonic, partial and other seizures types was based on the Commission on Epidemiology and Prognosis, 1993 International League against Epilepsy [30].

\section{Results}

Table I Demographic data of patients presenting with seizure

\begin{tabular}{|c|c|c|}
\hline Age & Frequency & Percent \\
\hline 1 month- 1year & 152 & 29.2 \\
\hline $1-3 \mathrm{yrs}$ & 142 & 27.3 \\
\hline $4-6$ yrs & 94 & 18.1 \\
\hline $7-12$ yrs & 132 & 25.4 \\
\hline Total & 520 & 100 \\
\hline \multicolumn{3}{|l|}{ Sex } \\
\hline Male & 300 & 57.7 \\
\hline Female & 220 & 42.3 \\
\hline Total & 520 & 100 \\
\hline \multicolumn{3}{|l|}{ Type of seizure } \\
\hline \multicolumn{3}{|l|}{ Generalised } \\
\hline GTC & 154 & 50 \\
\hline Tonic & 90 & 29 \\
\hline Clonic & 18 & 6 \\
\hline Myoclonic & 14 & 5 \\
\hline Absence & 16 & 5 \\
\hline Atonic & 16 & 5 \\
\hline Total & 308 & 100 \\
\hline \multicolumn{3}{|l|}{ Partial } \\
\hline Simple & 40 & 18.8 \\
\hline Complex & 80 & 37.7 \\
\hline Secondary generalised & 92 & 43.3 \\
\hline Total & 212 & 100 \\
\hline \multicolumn{3}{|l|}{ Fever } \\
\hline Present & 265 & 51 \\
\hline Absent & 255 & 49 \\
\hline \multicolumn{3}{|l|}{ Status epileptics } \\
\hline Present & 48 & 9 \\
\hline Absent & 472 & 91 \\
\hline
\end{tabular}

A total of 520 children were included of whom the incidence of seizures among different age group was: 1 month to 1 year $29.2 \%$ (152), $1-3$ years $27.3 \%$ ( 142 ), 4-6 years $18.1 \%$ (94) and 7 to 12 years was $25.4 \%$ (122). There were $300(57.7 \%)$ males and $220(42.3 \%)$ females with male to female ratio of 1.36:1.Fever was notably present in $51 \%$ of children at presentation. In generalized seizures, GTCS was seen in $50 \%$ of the children followed by tonic seizures which were present in $29 \%$. Myoclonic, clonic, atonic and absence seizures were seen equally (5\%).Among partial seizures, simple partial seizures were noted in $19 \%$, complex partial in $38 \%$ and partial seizures with secondary generalization was seen in $43 \%$. Status epilepticus was present in 48 $(9.2 \%)$ of children. 


\subsection{Table II Incidence of partial and generalized seizure in different age groups}

\begin{tabular}{|c|c|c|c|c|c|}
\hline & \multicolumn{2}{|c|}{ Seizure type } & \multirow[b]{2}{*}{ Total } \\
\hline & & & Partial & Genera] & \\
\hline \multirow[t]{8}{*}{$\mathrm{AGE}$} & 1 Month to 1 Yeat & Count & 84 & 68 & 152 \\
\hline & & $\%$ of Total & $16.2 \%$ & $13.1 \%$ & $29.2 \%$ \\
\hline & 1. 3 Years & Count & 50 & 92 & 142 \\
\hline & & $\%$ of Total & $9.6 \%$ & $17.7 \%$ & $27.3 \%$ \\
\hline & 4.6 Years & Count & 22 & 72 & 94 \\
\hline & & $\%$ of Total & $4.2 \%$ & $13.8 \%$ & $18.1 \%$ \\
\hline & $7-12$ Years & Count & 56 & 76 & 132 \\
\hline & & $\%$ of Total & $10.8 \%$ & $14.6 \%$ & $25.4 \%$ \\
\hline \multirow[t]{2}{*}{ Total } & & Count & 212 & 308 & 520 \\
\hline & & $\%$ of Total & $40.8 \%$ & $59.2 \%$ & $100.0 \%$ \\
\hline
\end{tabular}

$42 \%$ had partial seizures and $59 \%$ had generalized seizures. The incidence of general and partial seizures in different age group was in 1 month to 1 year partial was $52 \%$ and general was $48 \%$. In $1-3$ years age group partial was $35 \%$ and general the rest. In 4-6years age group partial was $23 \%$ and general $77 \%$. Beyond 7 years $42 \%$ had partial and the rest had general seizures.

\section{3 $\quad$ Fig I}

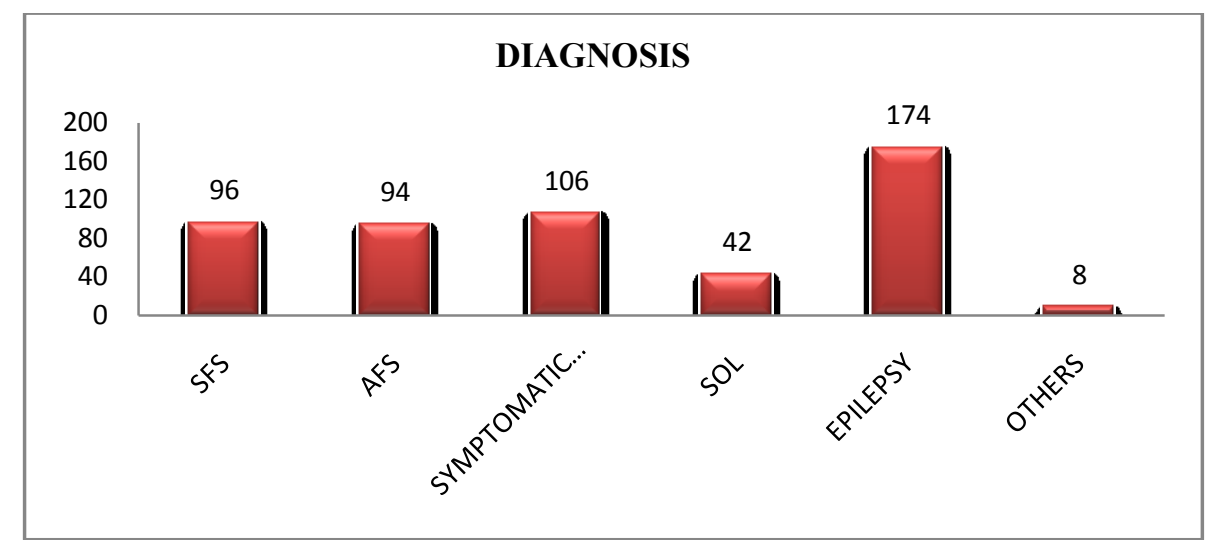

SFS-simple febrile seizures, AFS-atypical febrile seizures, SOL-space occupying lesion

In the present study SFS was found in 19\% (96), AFS in 18\% (94), symptomatic seizures in $20 \%$ (106), SOL in $8 \%$ (42), epilepsy in $33 \%$ (174) and others in $2 \%$ (8) of cases.

About $86.5 \%$ (450) of the children recovered normally. $6 \%$ recovered with deficit, $5 \%$ were either referred or discharged against medical advice and 3\% died. Mortality was largely seen in the symptomatic seizures (viral encephalitis, meningitis, intracranial bleed) as shown in TABLE III and Fig II

\section{$3.4 \quad$ Table III}

Outcome

\begin{tabular}{|l|r|r|r|r|}
\hline & Frequency & Percent & Valid Percent & $\begin{array}{c}\text { Cumulative } \\
\text { Percen1 }\end{array}$ \\
\hline Recovered & 450 & 86.5 & 86.5 & 86.5 \\
Recovered with deficit & 30 & 5.8 & 5.8 & 92.3 \\
Notrecovered & 24 & 4.6 & 4.6 & 96.9 \\
AMA abscond & 16 & 3.1 & 3.1 & 100.0 \\
Mortality & 520 & 100.0 & 100.0 & \\
Total & &
\end{tabular}




\subsection{Fig II}

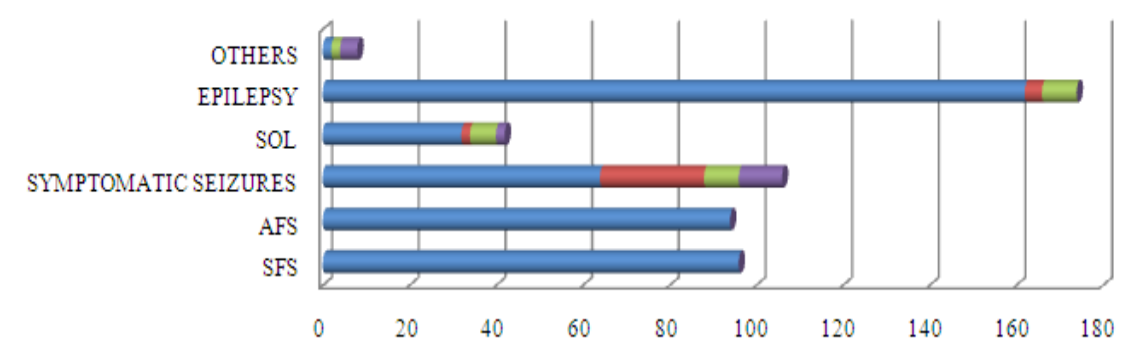

\begin{tabular}{|l|c|c|c|c|c|c|}
\cline { 2 - 7 } \multicolumn{1}{c|}{} & SFS & AFS & $\begin{array}{l}\text { SYMPTOMAT } \\
\text { IC SEIZURES }\end{array}$ & SOL & EPILEPSY & OTHERS \\
\hline$\square$ RECOVERED NORMALLY & 96 & 94 & 64 & 32 & 162 & 2 \\
\hline$\square$ RECOVERED WITH DEFICIT & 0 & 0 & 24 & 2 & 4 & 0 \\
\hline -REFERRED/AMA & 0 & 0 & 8 & 6 & 8 & 2 \\
\hline$\square$ MORTALITY & 0 & 0 & 10 & 2 & 0 & 4 \\
\hline
\end{tabular}

\subsection{Demographics and clinical seizure types}

\section{Discussion}

This was a hospital based prospective study of children admitted with acute episode of seizure in a tertiary care center in south India from Jan 2010 to Dec 2012. It aimed in studying demographics, clinical seizure types, etiologies and outcome during the hospital stay of those children. Most studies show high incidence of seizures in younger children with a decreasing frequency in older age group and more common in males $[19,21]$. Most children with seizures in our study were younger than 6 years of age. In our study the incidence of seizures among different age group was ; 1month to 1year-29.2\% (76/260),1-3 years $27.3 \%(71 / 260), 4-6$ years $-18.1 \%(47 / 260)$ and 7 to 12 years was $25.4 \%(61 / 260)$.This correlated with many studies[31-33]. Males had higher prevalence compared to females similar to other studies. [33-35] Seizures coexisted with fever in $51.5 \%$ of cases. Most studies show generalized seizures are much more common compared to partial seizure $[20,21,23,31,32]$ similar to our study. In the current study generalized tonic-clonic was commonest seizure type and partial seizure was common among children more than 7 years. Partial seizures represented $212(40.8 \%)$ of children in the current study. In our study we found that $81 \%$ of children presented with $1^{\text {st }}$ episode of seizures whereas $19 \%$ of children already had one or more episodes before. Among those presenting with recurrent episodes of seizures most of the cases were associated with epilepsy followed by febrile seizures. Also at the time of hospitalization $43 \%$ of children had seizures only once and $57 \%$ of had multiple episodes ( 2 or more). It was interesting to know that in our study, most of the children (88\%) presented with seizures during the day time, the rest presented during night.

\subsection{Etiological profile}

Whether routine neuroimaging should be done in all children admitted with acute episode of seizure is debated $[21,36]$. In our study abnormal neuroimaging was present in only $106(25 \%)$. We compared the type of seizures \& abnormal imaging \& found that $27 \%$ of partial seizures \& $14 \%$ of general seizures showed abnormality. Among SOL, NCC was seen in $20(4.7 \%)$ cases, tuberculoma in $8(1.8 \%)$ cases, others including benign neoplasms of brain. Febrile seizures (CFS) did not show any abnormality in CT which correlated with many studies. Most of other studies [34,37]done showed higher incidence of abnormality in imaging studies associated with seizures, but many studies were not generalized to all type of seizures like our study.AAP recommends lumbar puncture for febrile seizure children aged less than 12 months [38]. CSF analysis was done for 160 children out of 520,we found abnormality in 66 children (41\%)(Bacterial-60/ Viral-6) There are many possible etiologies of a first seizure attack in children, including infection, neurologic/developmental causes, traumatic head injury, toxins, and metabolic disturbances [20-22]. Febrile seizures have been reported to be one of the most common causes of seizure attack in children [19,20].Overall febrile seizures $(36.5 \%)$, seizure disorder (33.2\%), symptomatic seizures $(20 \%)$ and SOL were common etiologies. Among symptomatic seizures ,the following types were seen meningitis- $43 \%$ (46), encephalitis-18\%(20), camphor poisoning-13\%(14), post traumatic- $11 \%(12)$, hyponatremia-5\%(6), hypoglycemia-4\%(4), hypocalcemia-6\%(4).In our study. EEG was found to be abnormal in 70\% (364) of the studies cases. Focal epileptiform abnormality was described in (86/364) $24 \%$ \& generalized epileptiform abnormality was seen in $76 \%$ (278/364) similar to study by Mohd Ashraf et al[31].EEG abnormality was seen in 35\% (104 out of 190) of children with febrile seizures. Most of 
$90 \%$ of the EEG abnormality contributed from CFS. In symptomatic seizures $58 \%$ was abnormal. Most of the abnormality was seen with meningitis. Focal epileptiform discharges were associated with intracranial SOL.

\subsection{Primary outcome of acute seizure}

In our study, $86.5 \%(450)$ of the children recovered normally, $6 \%$ recovered with deficit, $5 \%$ were either referred or discharged against medical advice and 3\% died. Mortality was largely seen in the symptomatic seizures (viral encephalitis, meningitis, intracranial bleed). No mortality was seen with febrile seizures. All cases of death had refractory status epileptics, presented late to the hospital and succumbed within few hours of admission. Mortality rate during hospital course among children admitted with acute episode of seizure was similar with reports from other developing countries [20]. There was no significant difference in the outcome among males and females. Fever was not independently associated with increased mortality during the acute illness. Meningitis and encephalitis cause significant childhood mortality and morbidity [20, 22].

\section{Limitations of the study}

Outcome was defined as mortality during hospital stay and we were unable to study morbidities like neurological dysfunction and impact on scholastic performance. The details of other causes contributing for seizures like inborn error of metabolism could not be specified due lack of investigations. Multi centric prospective study is needed to find out details regarding these problems.

\section{Conclusions}

Acute episode of seizures are one of the commonest cause of hospitalization with high mortality. Febrile convulsions and CNS infections were common causes of seizures in febrile children. Seizures were more common in age 1 month to 1year. Neuroimaging should be advised in all afebrile children and in children with partial seizures. CNS infections like meningitis and encephalitis, neurocysticercosis can be prevented with improvement in health care facilities. Group of children presenting with unprovoked seizure require long term follow up studies including neurophysiologic studies and neuroimaging (CT or MRI) for better understanding of childhood seizure disorder in developing countries.

\section{References}

[1]. Nelson KB. Ellenberg J.H In: Febrile Seizures. Nelson KBEJH, editor. New York, Raven Press; 1981.

[2]. Sadleir LG, Scheffer IE. Febrile seizures. Bmj. 2007; 334:307-311. doi: 10.1136/bmj.39087.691817.AE.

[3]. Huang CC, Chang YC, Wang ST. Acute symptomatic seizure disorders in young children--a population study in southern Taiwan. Epilepsia. 1998; 39:960-964.

[4]. Hauser WA. The prevalence and incidence of convulsive disorders in children. Epilepsia. 1994; 35 Suppl 2:S1-6.

[5]. Verity CM, Greenwood R, Golding J. Long-term intellectual and behavioral outcomes of children with febrile convulsions. N Engl J Med. 1998;338:1723-1728.

[6]. Akpede GO, Abiodun PO, Sykes RM. Pattern of infections in children under-six years old presenting with convulsions associated with fever of acute onset in a children's emergency room in Benin City, Nigeria. J Trop Pediatr. 1993; 39:11-15.

[7]. Birbeck GL. Seizures in rural Zambia. Epilepsia. 2000; 41:277-281.

[8]. Waruiru CM, Newton CR, Forster D, New L, Winstanley P, Mwangi I, Marsh V, Winstanley M, Snow RW, Marsh K. Epileptic seizures and malaria in Kenyan children. Trans R Soc Trop Med Hyg. 1996; 90:152-155.

[9]. Iloeje SO. Febrile convulsions in a rural and an urban population. East Afr Med J. 1991;68:43-51.

[10]. Owusu-Ofori A, Agbenyega T, Ansong D, Scheld WM. Routine lumbar puncture in children with febrile seizures in Ghana: should it continue? Int J Infect Dis. 2004; 8:353-361.

[11]. Iloeje SO. Paediatric neurologic emergencies at the University of Nigeria Teaching Hospital, Enugu. West Afr J Med. 1997;16:8084

[12]. Carter JA, Mung'ala-Odera V, Neville BG, Murira G, Mturi N, Musumba C, Newton CR. Persistent neurocognitive impairments associated with severe falciparum malaria in Kenyan children. J Neurol Neurosurg Psychiatry. 2005; 76:476-481.

[13]. Boivin MJ, Bangirana P, Byarugaba J, Opoka RO, Idro R, Jurek AM, John CC. Cognitive impairment after cerebral malaria in children: a prospective study. Pediatrics. 2007; 119:e360-6.

[14]. Annegers JF, Hauser WA, Elveback LR, Kurland LT. The risk of epilepsy following febrile convulsions. Neurology. 1979;29:297303.

[15]. Carter JA, Neville BG, White S, Ross AJ, Otieno G, Mturi N, Musumba C, Newton CR. Increased prevalence of epilepsy associated with severe falciparum malaria in children.Epilepsia. 2004; 45:978-981.

[16]. Ngoungou EB, Dulac O, Poudiougou B, Druet-Cabanac M, Dicko A, Mamadou Traore A, Coulibaly D, Farnarier G, Tuillas M, Keita MM, Kombila M, Doumbo OK, Preux PM. Epilepsy as a consequence of cerebral malaria in area in which malaria is endemic in Mali, West Africa.Epilepsia. 2006; 47:873-879.

[17]. Ngoungou EB, Koko J, Druet-Cabanac M, Assengone-Zeh-Nguema Y, Launay MN, Engohang E, Moubeka-Mounguengui M, Kouna-Ndouongo P, Loembe PM, Preux PM, Kombila M. Cerebral malaria and sequelar epilepsy: first matched case-control study in Gabon. Epilepsia.2006; 47:2147-2153.

[18]. Friedman MJ, Sharieff GQ. Seizures in children. Pediat Clin North Am. 2006;13:257-277.

[19]. Martindale JL, Goldstein JN, Pallin DJ. Emergency department seizure epidemiology. Emerg Med Clin North Am. 2011 Feb; $13(1): 15-27$.

[20]. Idro R, Gwer S, Kahindi M. The incidence, aetiology and outcome of acute seizures in children admitted to a rural Kenyan district hospital. BMC Pediatr. 2008; 13:5. 
[21]. Chen CY, Chang YJ, Wu HP. New-onset Seizures in Pediatric Emergency. Pediatr Neonatol.2010; 13(2):103-111.

[22]. Murthy JMK, Yangala R. Acute symptomatic seizures-incidence and etiological spectrum: a hospital-based study from South India. Seizure. 1999; 13:162-165.

[23]. Huang CC, Chang YC, Wang ST. Acute Symptomatic Seizure Disorders in Young Children-A Population Study in Southern Taiwan. Epilepsia. 1998; 13(9):960-964.

[24]. Basu S, Ramchandran U, Thapliyal A. Clinical profile and outcome of pediatric neuro-cysticercosis: A study from Western Nepal. J Pediatr Neurol. 2007; 13:45-52.

[25]. Rayamajhi A, Singh R, Prasad R, Khanal B, Singhi S. Study of Japanese encephalitis and other viral encephalitis in Nepali children. Pediatr Int. 2007; 13(6):978-984.

[26]. Allen Hauser W, Beghi E. First seizure definitions and worldwide incidence and mortality.Epilepsia. 2008; 13(Suppl. 1):8-12.

[27]. Geerts A, Arts WF, Stroink H, Peeters E, Brouwer O, Peters B. Course and outcome of childhood epilepsy: A 15 -year follow-up of the Dutch Study of Epilepsy in Childhood. Epilepsia.2010; 13(7):1189-1197.

[28]. Shakya KN, Shrestha R, Baral MR. Epilepsy in children: an epidemiological study at Kathmandu Medical College Teaching Hospital Kathmandu. Kathmandu Univ Med J.2003;13(1):14-19.

[29]. Finkenbine RD, Acland S, Finkenbine SS. Epilepsy at four Kaski Village health posts.International workshop on epilepsy. Proceedings of EPICADEC and Department of Psychiatry, IOM; 1996 Apr 15; Kathmandu, Nepal. 1996. pp. 24-33.

[30]. Commission on Epidemiology and Prognosis. International League Against Epilepsy. Guideline for epidemiologic studies on epilepsy. Epilepsia. 1993; 13:592-596.

[31]. Mohd Ashraf1, Mohd Irshad1, Javed Chowdhary1, Reyaz A Malla1and YasmeenaAkhter.Computed tomographic study in young epileptics in Kashmir, IndiaAl Ameen J Med Sci 2013; 6(3) :272-277

[32]. MB Duggan- Epilepsy in Ugandan children, seizure pattern, age of onset \& associated findings. African health sciences, Sep 2010 $\mathrm{V}(10)$

[33]. Selena H Banu, Naila Z Khan - Profile of childhood epilepsy in Bangladesh- Developmental medicine \& Child neurology 2003; 45 $477-482$

[34]. Narendrasaini et al. To determine the incidence and type of neuroimaging abnormalities in children presenting with a first afebrile seizure.

[35]. Neeraj Jain and VibhaMangal .Role of EEG and CT scan in partial seizures in children. International Journal of Medicine and Medical Sciences Vol. 3(5), pp. 161-163, May 2011.

[36]. Goldstein JL. Evaluating new onset of seizures in children. Pediatr Ann. 2004; 13(6):368-374

[37]. Ramesh Baheti, BD Gupta, Rajesh Baheti. A study of CT and EEG findings in patients with generalized or partial seizures in Western Rajasthan JIACM 2003; 4(1): 25-9.

[38]. Academy of Pediatrics. Provisional Committee on Quality Improvement, Subcommittee on Febrile Seizures. Practice parameter: the neurodiagnostic evaluation of the child with a first simple febrile seizure. Pediatrics. 1996; 13:769-772. 